\title{
LOCALIZED “ALVEOLAR CELL" TUMOUR WITH BRONCHIAL INVOLVEMENT
}

\author{
BY
}

\author{
W. J. HANBURY AND I. M. HILL \\ From St. Bartholomew's Hospital, London
}

(RECEIVED FOR PUBLICATION DECEMBER 14, 1955)

The literature concerning the disease or group of related conditions, variously designated as alveolar cell tumour, pulmonary adenomatosis, and bronchiolar carcinoma, has been extensively reviewed by Neubuerger and Geever (1942), Ikeda (1945), Swan (1949), Hutchison (1952), and by Storey, Knudtson, and Lawrence (1953). The last of these added all the previously reported authentic cases to their own, thus making a total of 217 at that time.

This paper records a further case of a tumour of "alveolar cell" type, which is of particular interest on account of its unusual involvement of small bronchi and bronchioles. For this reason the tumour presents difficulties in precise classification, as between a so-called "alveolar cell" tumour and a peripheral bronchogenic or bronchiolar adenocarcinoma. The tumour is also of interest because of its localized nature, rendering it amenable to surgery, and on account of the radiological appearances which provided the first indication of a pulmonary neoplasm.

\section{CASE History}

A housewife, aged 63, had complained of numbness in the fingers of the right hand during the four weeks before admission and was referred to the diabetic clinic for stabilization, having a history of diabetes over a period of 15 years. During examination a hard mass was felt in the left hypochondrium with the physical signs of a lesion of the transverse colon. A barium enema examination showed no evidence of carcinoma of the colon, but two calcified cysts were seen, the larger one adjacent to the transverse colon and spleen and a smaller one low down on the right side. On fluoroscopy a shadow was seen in the upper lobe of the left lung, and subsequent postero-anterior (Fig. 1) and left lateral films and tomograms were interpreted as showing a left hilar mass with an anterior segmental lesion associated. There were no surrounding satellite shadows and the whole appearance was more suggestive of primary bronchial carcinoma than of pulmonary tuberculosis. The rest of the lung fields was clear.
The patient had a slight unproductive cough, had never had haemoptysis, had no chest pain, and had not noticed any loss of weight. Though she denied shortness of breath, she was seen to be slightly dyspnoeic on undressing. Examination of the chest revealed poor expansion for a woman, with slight limitation on the left. Air entry was diminished over the left side of the chest anteriorly, where there was some bronchial breathing. Active grade III clubbing of the fingers was present and there was no clinical evidence of extrathoracic metastases. She was regarded as a poor-risk subject for pneumonectomy, but as a possible candidate for left upper lobectomy.

Examination of the sputum was repeatedly negative for $M$. tuberculosis, but no search for tumour cells was made. On bronchoscopy the only abnormality seen was a constant trickle of clear mucus from the left upper lobe orifice in an otherwise dry bronchial tree. No significance was attached to this finding at the time. The bronchoscopy gave no evidence of carcinoma or an infective lesion of the left upper lobe, and suggested that the lesion was resectable by left upper lobectomy. Thoracotomy was decided upon

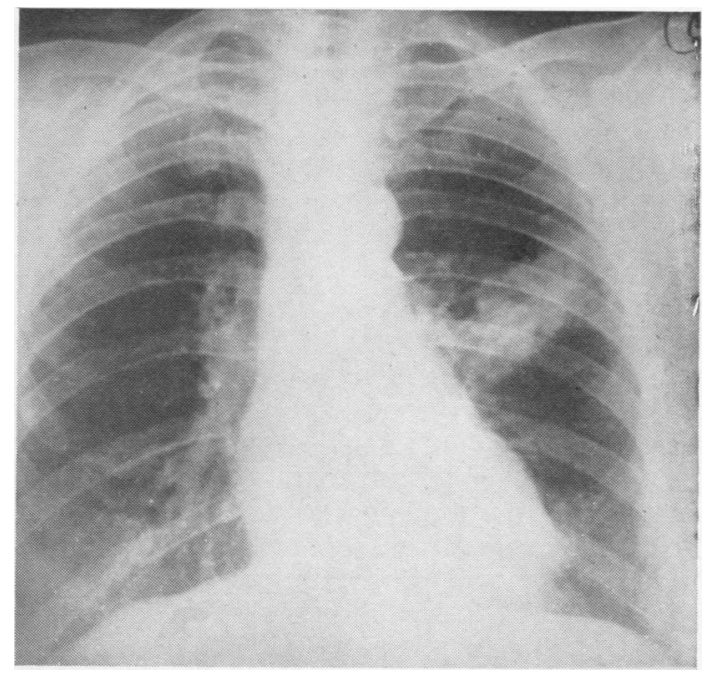

Fig. 1.-Radiograph of the chest showing a shadow in the left upper lobe. 
with the presumptive diagnosis of left upper primary bronchial carcinoma. The nature of the abdominal calcified cysts was, and still is, not determined.

At operation a hard, puckered mass was found in the anterior segment of the left upper lobe; there were a few calcified lymph nodes over the left pulmonary artery, but no hilar mass and no other palpably abnormal lymph nodes in the left chest. A dissection left upper lobectomy was carried out easily with the macroscopic diagnosis of primary bronchial carcinoma. Progress was entirely uneventful, with immediate expansion of the lower lobe to fill the left chest.

\section{Pathology}

The specimen consisted of the upper lobe of a left lung which weighed 250 grams after fixation and slicing. The pleura was thickened and puckered over a peripheral tumour (Figs. 2, 3, and 4 ), the cut surface of which showed an irregular central whitish area, surrounded by a zone of semitranslucent consolidated lung tissue with illdefined margins. The tumour measured approximately $7 \times 3 \times 4 \mathrm{~cm}$. and was situated in the anterior segment, extending towards the hilum in relation to branches of the anterior bronchus. There was also a close relationship with an accessory bronchus arising from the main lingular bronchus $0.7 \mathrm{~cm}$. from its origin (Fig. 3). The remaining lung tissue appeared normal, no other tumour nodules being found, and the hilar lymph nodes showed no enlargement or macroscopic evidence of neoplastic infiltration.

\section{Histology}

The structure of most of the tumour shows a characteristic "alveolar cell" pattern (Fig. 5). The pulmonary alveolar walls remain intact and are lined by tall, regular, columnar epithelial cells with small basal nuclei showing few mitoses. Towards the periphery many alveoli and alveolar ducts contain clumps of tumour cells lining only part of their walls (Fig. 6). Secretion of mucus is much in evidence and is clearly demonstrated by staining with mucicarmine (Fig. 7), the mucus being both intracellular as well as lying free within the alveoli. In a broad zone around the tumour there are also numerous intra-alveolar macrophages mingled with the mucus, and there are occasional areas of organizing pneumonia and fibrosis. No actual necrosis can be seen, although there is evidence of mucoid degeneration of tumour cells. While many of the bronchioles maintain their normal structure, although closely invested by tumour, others show partial or complete replacement of their normal ciliated epithelium by clear- celled epithelium of tumour type (Figs. 8 and 9). Some of the smallest cartilage-containing bronchi show a similar change (Fig. 10); they appear to branch directly into tumour-containing alveolar ducts and alveoli, their epithelium showing an abrupt transition. Serial sections do not show the ordinary form of carcinomatous destruction with ulceration of bronchi and bronchioles, but appearances suggest that their epithelium has been replaced by the growth of tumour cells along their

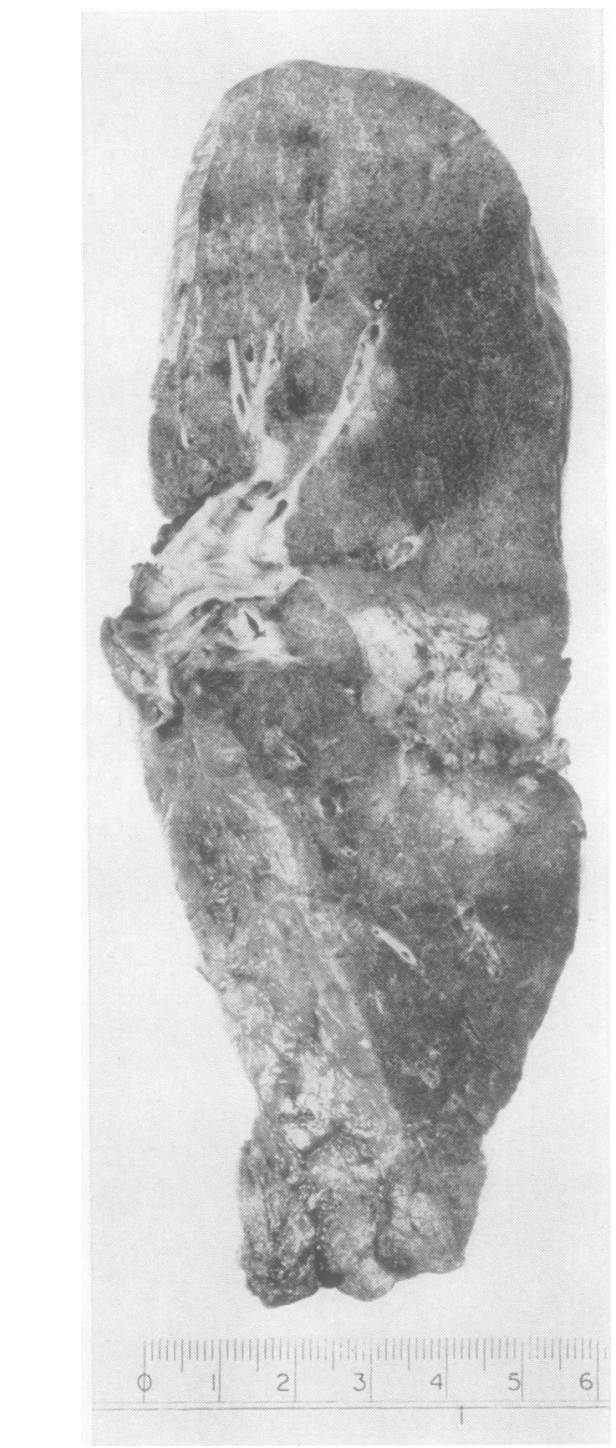

FIG. 2.-Cut surface of the left upper lobe, showing the tumour in the anterior segment. The anterior and apico-posterior bronchial divisions are also shown. 


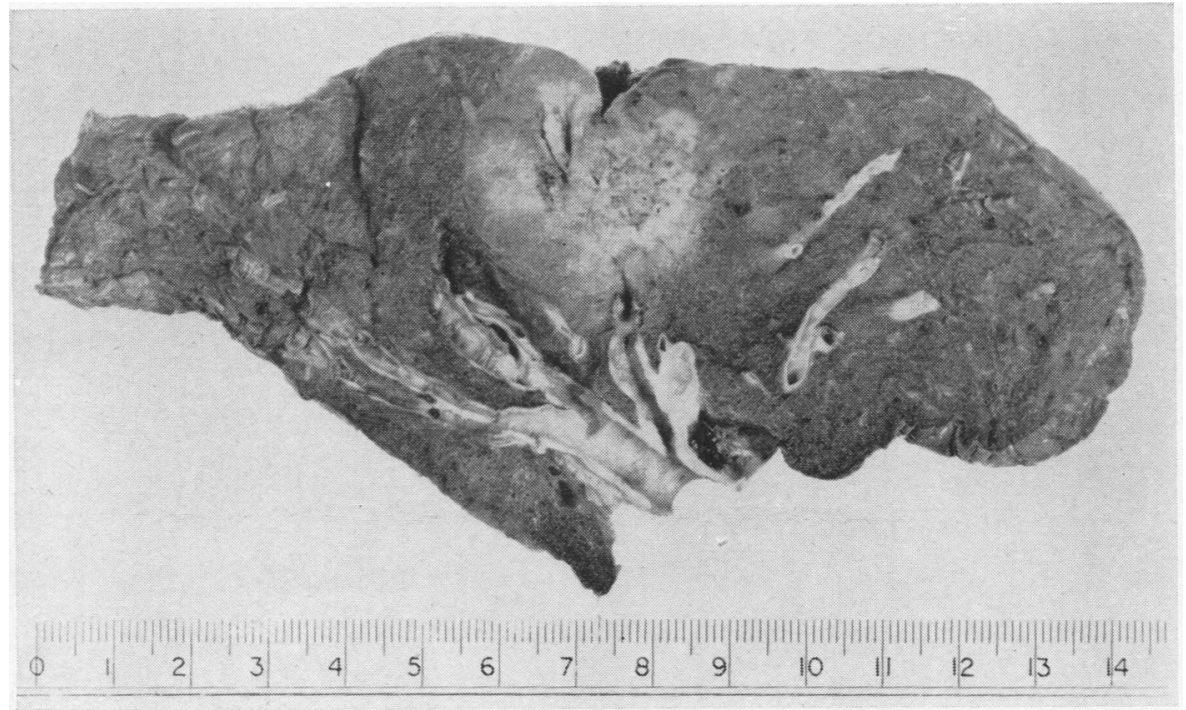

Fig. 3

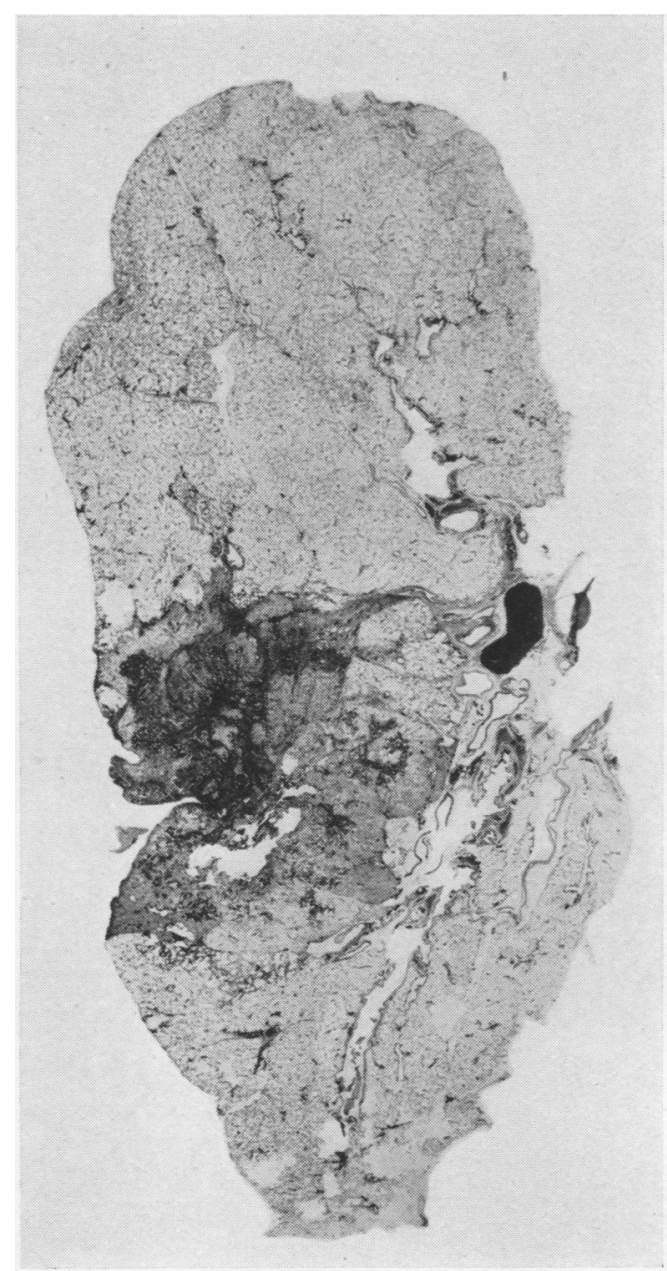

Fig. 4

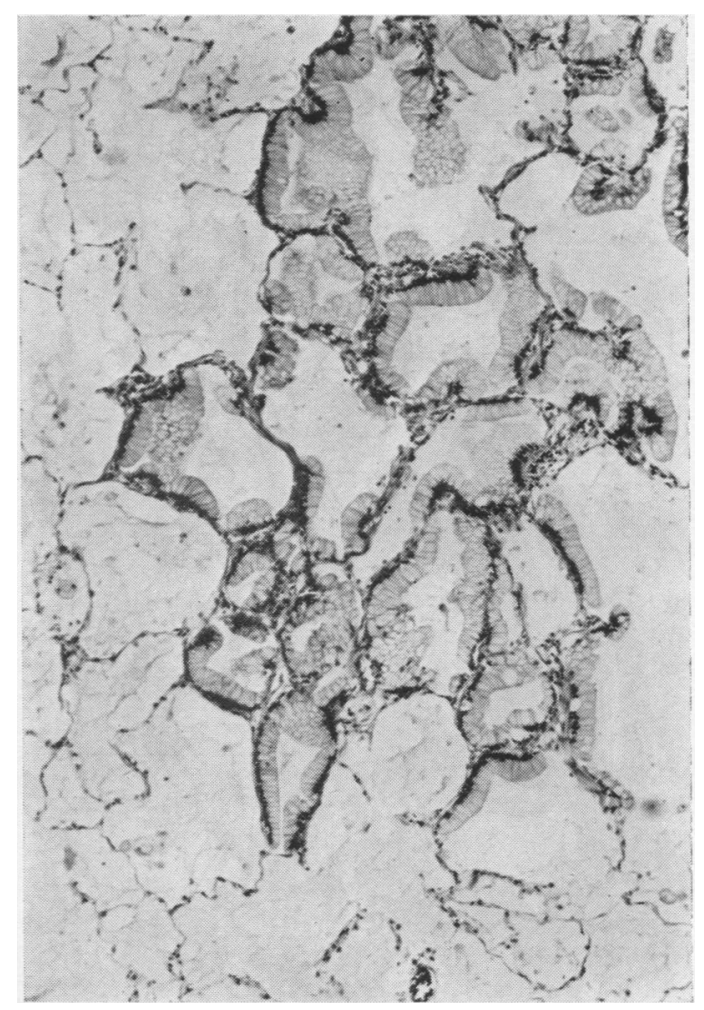

Fig. 5

Fig. 3.-Cut surface of the left upper lobe, showing the tumour in relation to an accessory bronchus arising from the main lingular bronchus.

Fig. 4.-Large histological section of the left upper lobe for comparison with Fig. 3 showing the extent of the tumour. (Haematoxylin and eosin, $\times 1$.)

Fig. 5.-Alveoli lined by tumour cells. (Haematoxylin and eosin, $\times 70$.) 

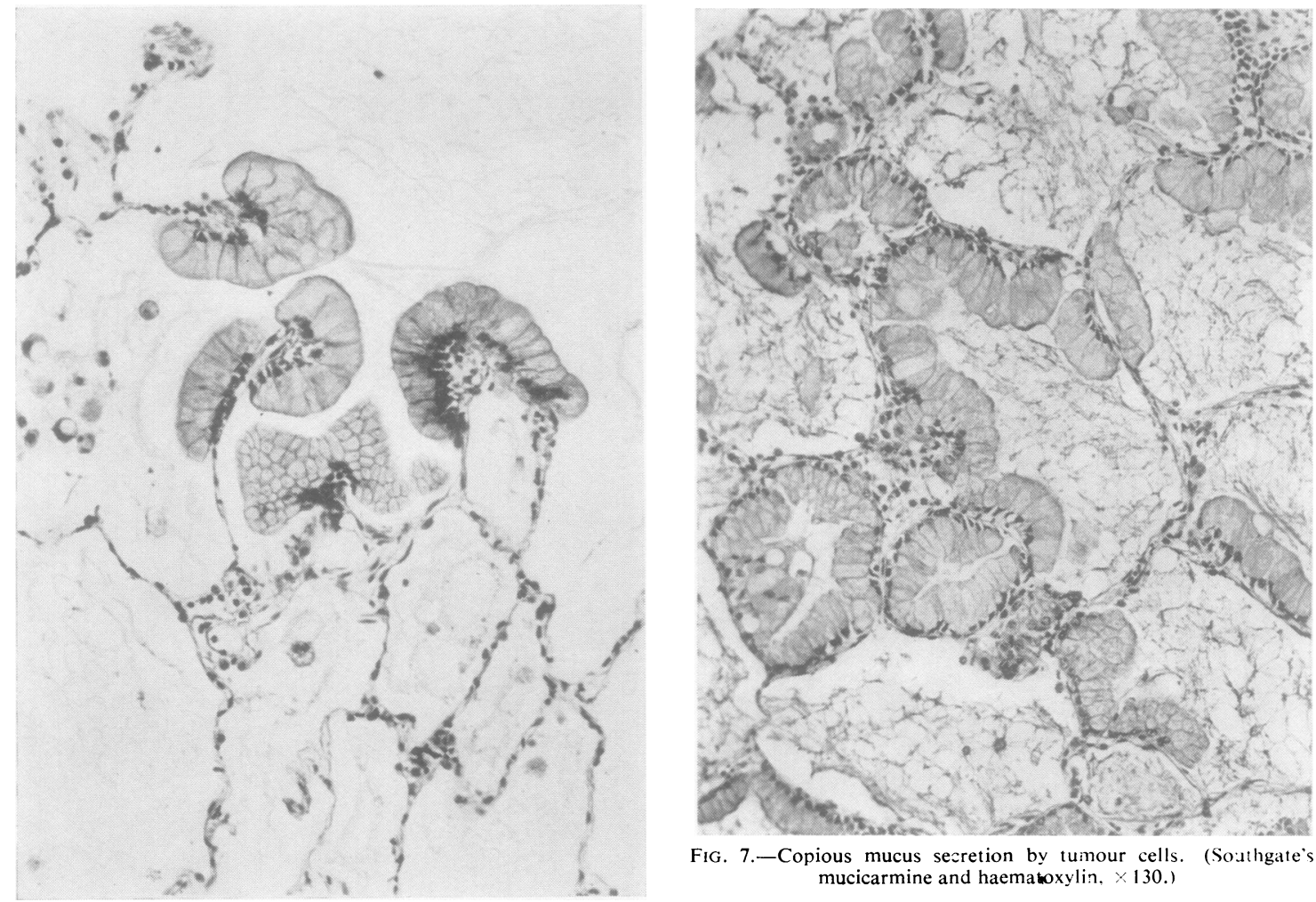

FIG. 7.-Copious mucus secretion by tumour cells. (Southgate's mucicarmine and haematoxylin, $\times 130$. )

FIG. 6. - Small clumps of tumour cells at the periphery of the growth. (Haematoxyl in and eosin, $\times 165$.)

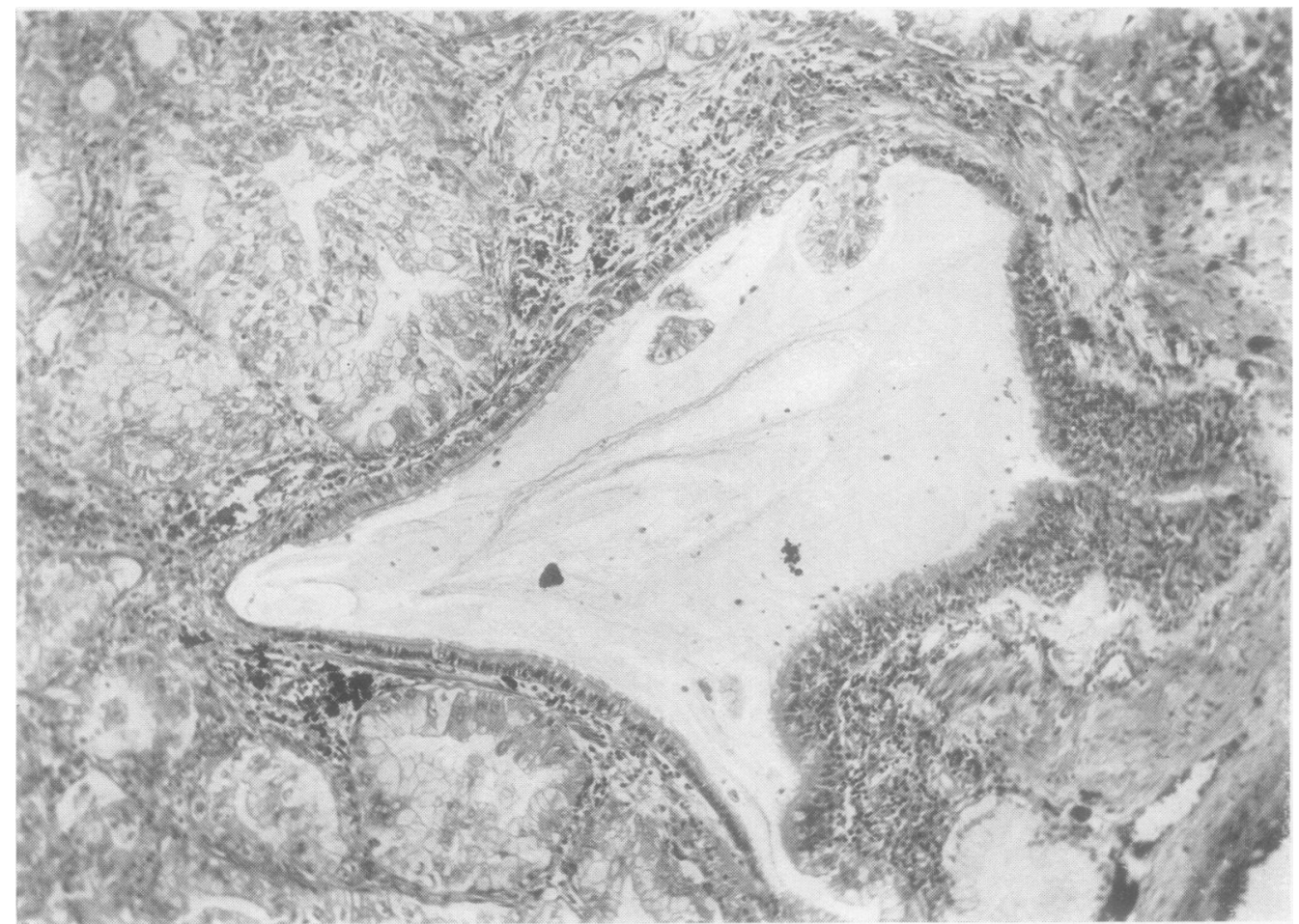

FIG 8-A bronchiole closely invested by tumour-lined alveoli and showing two small tumour nodules on the epithelial surface. (Haematoxylin and eosin. 100.) 


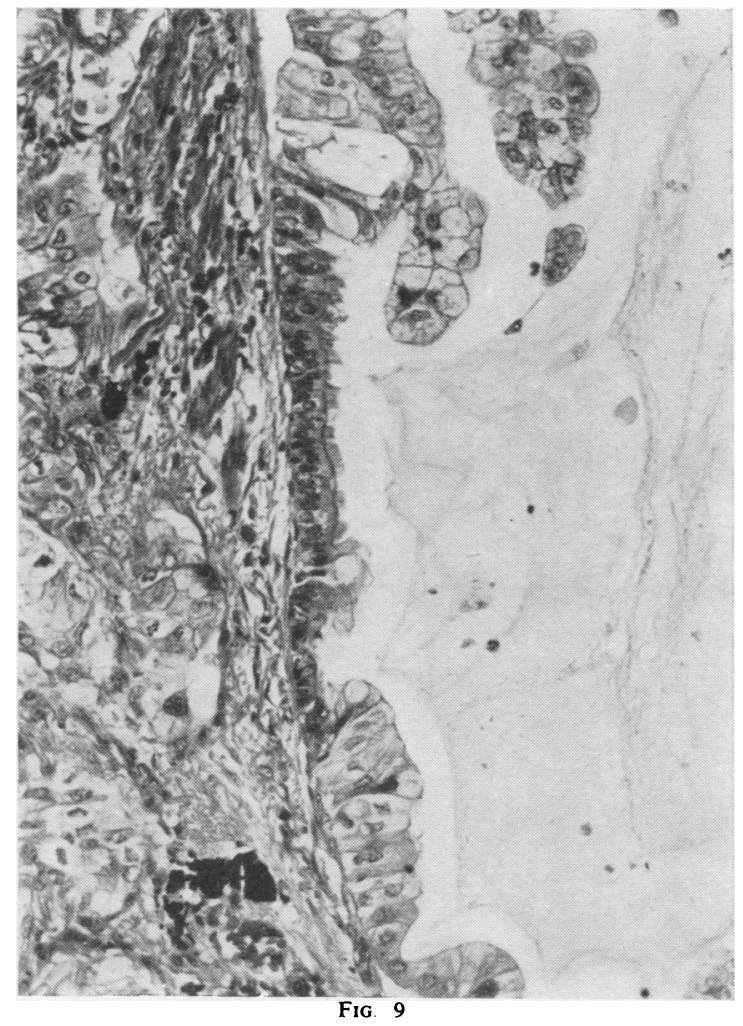

FIG. 9.-Part of a bronchiolar wall, showing a central area of normal ciliated epithelium which is replaced on either side by tumour epithelium. (Haematoxylin and eosin, $\times 180$.)

FIG. 10.-A small cartilage-containing bronchus, showing direct branching into tumour-lined alveolar ducts and alveoli. (Haematoxylin and eosin, $\times 60$.)

lumina, and in some instances that intrabronchial metastases may have occurred. There is no real evidence of bronchial or bronchiolar mucosa showing transitional stages from hyperplasia to neoplasia.

No permeation of lymphatic vessels can be seen, and there are no metastases in sections of seven hilar lymph nodes.

\section{Discussion}

The difficulty in proving the origin of the "alveolar cell" tumours, together with their diversity of structure and extent, has led to much difference of opinion as to their nomenclature, the criteria for their diagnosis, and their classification into one or more groups of tumour. It is not intended in this paper to review all these differ-

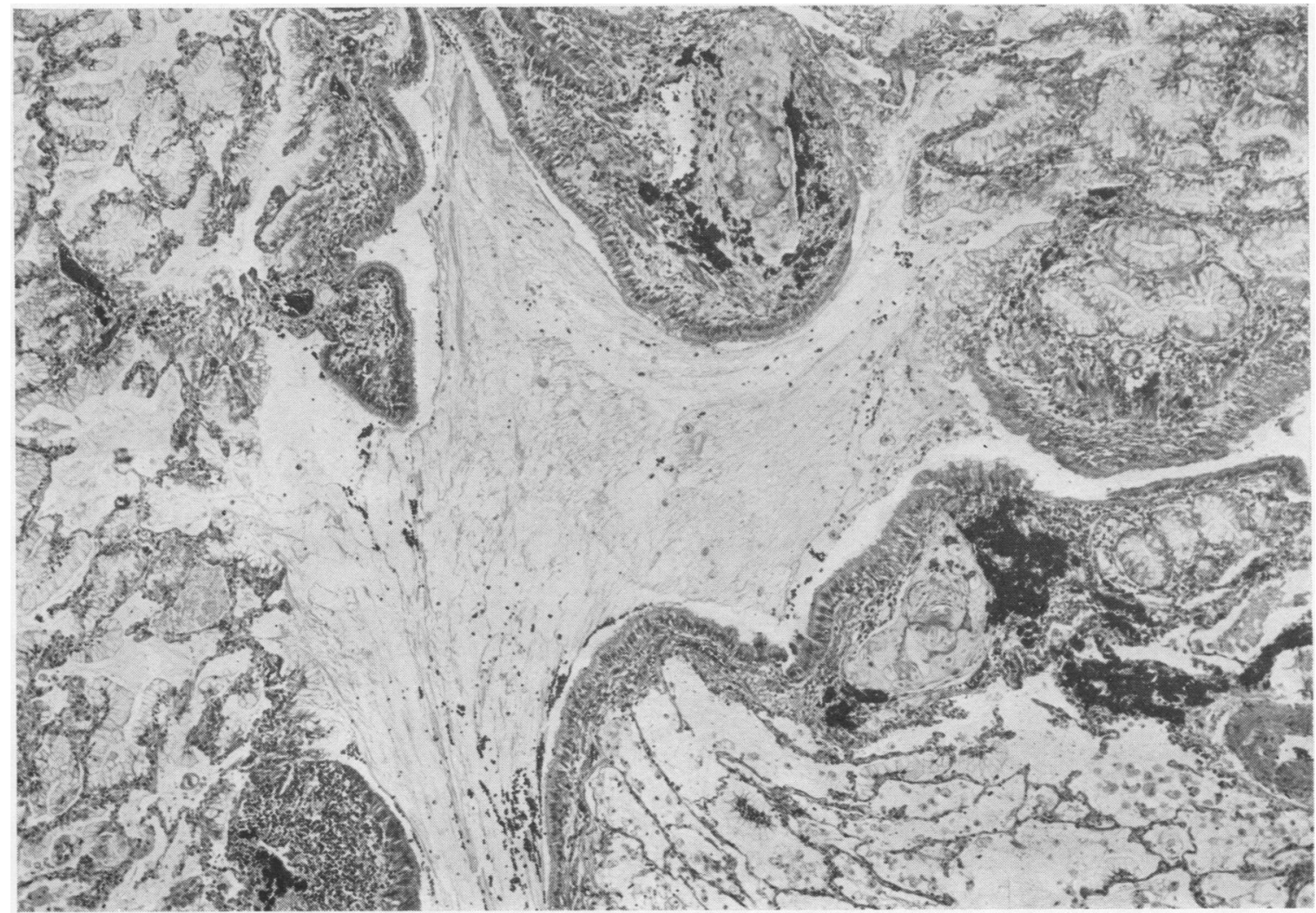

FIG. 10 
ences of opinion, but some raise a few points of interest in relation to the present case.

One of the usually accepted diagnostic criteria is the absence of an intrinsic tumour of the bronchus, although on some occasions bronchial erosion and ulceration by tumour from without has been observed (Neubuerger and Geever, 1942 ; Ikeda, 1945 ; Watson and Smith, 1951). In the present case there is certainly neoplastic involvement of some of the smallest bronchi and bronchioles, which does not appear to be due to direct erosion, in the sections examined. The tumour could therefore be classified either as a bronchogenic or bronchiolar adenocarcinoma with marked peripheral alveolar spread, or as an "alveolar cell" tumour with an unusual degree of bronchial involvement. However, a more logical view would be to regard it simply as a variety of peripheral adenocarcinoma of the lung.

As regards the extent of the tumour, the number of reported cases in which the growth was found localized in a segment of a lobe is much smaller than the number where the disease has been more widespread, but the time at which a diagnosis was made may well account for this difference. Storey and others (1953) summarized the radiological findings of 153 reported cases, $26 \%$ of which showed a solitary peripheral nodule and $8 \%$ an ill-defined area of pneumonia in a single lobe on first examination. They denied that there is convincing evidence of multicentric origin, and the tumour in the present case is certainly well localized. The small, apparently isolated clumps of tumour cells at the periphery of the growth and in some of the bronchioles could be accounted for by intrabronchiolar metastases, and there is no real evidence pointing to multicentric origin.

With regard to the behaviour of these tumours, there is no universal agreement as to whether pulmonary adenomatosis and bronchiolar or alveolar cell carcinoma are one and the same condition. Storey and others (1953) believe that they are the same, and consider resection to be the only hopeful treatment. Although the present tumour is 0 regarded as a carcinoma, there is little histological $\frac{D}{=}$ evidence of malignancy as judged by the usually $\frac{\bar{\omega}}{\vec{D}}$ accepted criteria for other types of carcinoma.

The possibility that the tumour may be a metastasis from a carcinoma elsewhere in the body cannot be entirely excluded, but is highly improb- ? able, the patient remaining very well nine months $\overrightarrow{\vec{\omega}}$ after the operation.

From a clinical standpoint, the case presented $\vec{x}$ no clearly diagnostic features. There were no symptoms directly referable to the chest, the radio- $\vec{\sim}$ logical appearance was at first suggestive of tuber- $\vec{\omega}$ culosis, sputum was surprisingly scanty in view $\underset{\omega}{\omega}$

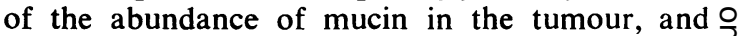
bronchoscopy was essentially negative.

\section{SUMmary}

A case of an "alveolar cell" type of carcinoma $\vec{\theta}$ of the lung is reported. The tumour was localized oु in the left upper lobe, being discovered radiologically in a patient attending a diabetic clinic, there having been no symptoms referable to the chest. Lobectomy was successfully performed, $\bar{D}$ and pathologically the tumour showed an unusual $\frac{\circ}{D}$ relationship to the smaller bronchi and bronchioles. Some of the differences of opinion in regard to $\overrightarrow{\overrightarrow{0}}$ "alveolar cell" tumours are briefly discussed in relation to this case.

We are indebted to Dr. G. Simon for the radiograph, Mr. J. W. Miller for histological sections, Mr. 응 N. K. Harrison for the photographs, and Dr. G. S. Sansom for the photomicrographs. We would also like to thank Professor J. W. S. Blacklock for helpful 3 criticism.

\section{REFERENCES}

Hutchison, H. E. (1952). Cancer, 5, 884

Ikeda, K. (1945). Amer. J. clin. Path., 15, 50. Ikeda, K. (1945). Amer. J. clin. Path., 15, 50.
Neubuerger, K. T., and Geever, E. F. (1942). Arch. Path. (Chicago),
33, 551.

Storey, C. F., Knudtson, K. P., and Lawrence, B. J. (1953). J. thorac. Surg., 26, 331.

Swan, L. L. (1949). Arch. Path. (Chicago), 47, 517.
Watson, W. L., and Smith, R. R. (1951). J. Amer. med. Ass., 147, 7. Љ 